\title{
Analysis of China's Stock Market in Year 2015
}

\author{
Jiaqi Li \\ North China Electric Power University 2 Beinong Road Huilongguan Town Changping District \\ Beijing China
}

834733817@qq.com

Keywords: Stock market; Mad cow; Tumble; High leverage; Shorting system

\begin{abstract}
Year 2015 is bound to be unforgettable for Chinese stock market and for hundreds of thousands of investors. Began with a bull market which evolved to a mad one, then a terrible stock disaster occurred, the whole market lost its crash liquidity. Stock index slumped dozens of points, sometimes even more than one hundred points a day. Almost all stock in the market dropped a half to its original value. Everything was out of control. Regulatory authority stepped in and tried to rescue the market, but it was interfered by the depreciation expected of RMB, so the rescue operation didn't play a proper roll which it should be. Two horrible market fusing mechanism also caused an unprecedented fall and aggravated panic of the market. All of these up and downs just happened in six months, like a dream. Every point in A-share market in year 2015 was filled with tears, sweat and blood. This paper will restore and analyze the thrilling and exciting roller coaster ride of stock market in year 2015 from market index, stock block and specific stock tendency.
\end{abstract}

\section{Analysis of Market Index}

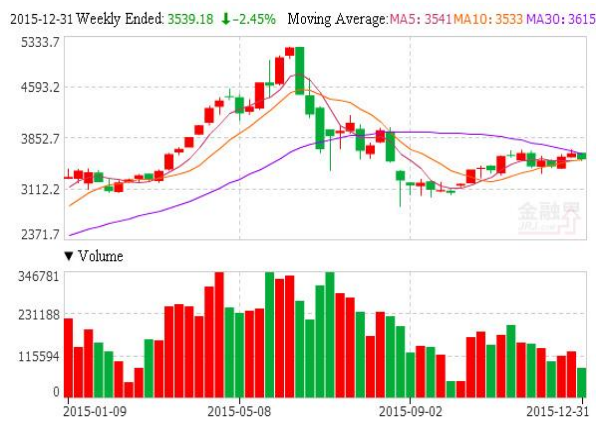

Figure 1. Shanghai Composite Index

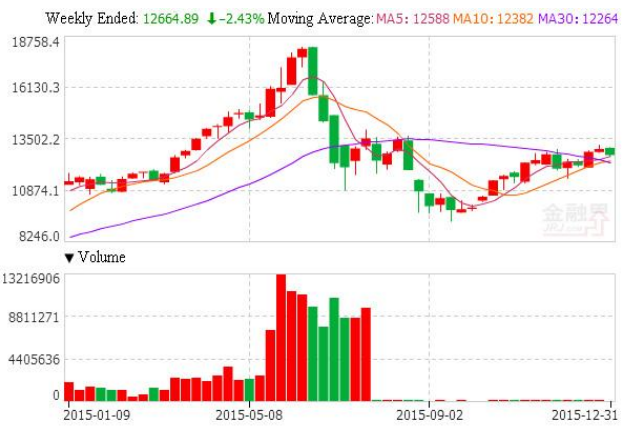

Figure 2. Shenzhen Component Index

Stage of Energy Accumulation (From Jan.5 - Mar.13). During this period, Shenzhen Component Index, Small and Medium Enterprise Board (SME board), Second-board Market rose 6.35\%, $26.93 \%, 40.58 \%$ each. Almost 2283 individual stocks edged higher at the same time. Among the stocks, 320 had a rise which was more than 50\%, 58 had their price doubled. Slip also existed, but the falling range was very slight. There were only 404 individual stocks had a small drop.

Stock in pannikin was very popular with investors.

Analysis: In order to create a bull market which can help to ease debt burden and promote economic transformation, the golden age of Chinese stock market came. But with the rapid propulsion of finance innovation, financial supervision is nothing but an empty shell under the name of finance innovation. Against the background of a loose regulation, securities traders exploited new ways to explore their investments. Even banks tried to avoid restrictions by a variety of ways, and had an active involvement in stock market with a way which seemed to be compliance. Individual investors put a large number of money into stock market directly and indirectly without scruple. For a short while, leverage ratio of the market increased rapidly, market structure became very unstable. However, a mad bull market was bred in the violent shock in Jan.2015. 
A Surge Stage (From Mar.16 - Jun.12).During this period, there were 2691 individual stock rose in whole A-share market, only 3 stocks had a decline. Except suspension, rates of stock price inflation almost reached 100\%. 2235 individual stock, accounted for $80 \%$ of the whole A-share market, whose price had a rise rate more than 50\%. 1129 individual stock's price doubled. Four representative stock indexes all had a climb, whose rise rate was more than a half. The boom of stock market was a magic in A-share market's history.

Analysis: Chinese economic didn't have a recovery in this time so it was not the reason for the booming of stock market. Due to a lot of advantaged policies published by the government market was in a active condition. Investors' confidence to stock market also enhanced day by day. Everyone wanted to get a sum of money from the bull market. Specific reasons for the booming are listed as followed:

(1) The Central Bank of China turned down deposit credit rate and deposit reserve rate frequently in these three months .Meanwhile, it created a easy environment with a high-liquidity currency policy by various currency tools for targeted easing such as Pledged Supplementary Lending. A moderately easy money policy became the new tendency.

(2) OTC fund had a lot of enthusiasm to enter the market. No matter institutions or retail investors, when the rate of bank deposit and lending declined, they all put a great number of money into the market. According to statistics, in March and April in 2015, new stock account added 1669 thousand, the link relative rose ratio was $46.5 \%$.

(3) High lever in stock market facilitated the form of mad cow. Stock leverage in China reached a high level of $10 \%$, it was so rare to see such a high leverage around the world. A high leverage means investors can get fund to buy stocks through securities margin trading, then they can sell stocks which they borrowed before to make a profit. This is an important reason for the rapid surge of stock index during March to June.

Tumble (Time: June 15 - August 26). Within 52 trading days, a disastrous tumble happened in large-cap stocks. Shanghai Composite Index (SCI) fell 40.31\%. Shenzhen Component Index fell 45.30\%. SMEs board declined 44.35\% and Growth Enterprise Board (GEB) declined 51.53\%. During this period, over 30 trillion yuan had been evaporated from the total market value of A-shares. According to statistics, during the above tumble period, among all of the A-shares, only 102 stocks rose. As many as 2498 stocks fell, including 1541 stocks, which fell over 50\%. It is noteworthy that (quasi) limits down for thousands of shares have happened 17 times in the A-shares market within the year.

Analysis: Highly Leveraged Funding. In the stock market, leverage means borrowing money to speculate in stocks. Once the stock market declines, terrible stampedes, and even financial crises will happen. In a bull market in 2015, the leverage ratios in Shanghai and Shenzhen stock market exceeded $10 \%$. Higher leverage means higher risk. According to statistics, throughout the past 30 years, only Taiwan set a record of $6 \%$ leverage ratio. Thus, it can be seen that if A-shares were a big casino, gamblers in it were at the highest risk on a global extent. When some investors gradually found risks and were about to withdraw, they found that under the background that plenty of leverage funds entered the market, once the stock market declined, thousands of shares would fall together spectacularly.

The Shorting System Intensified Panic in the Market. In April 2015, when a stock market bubble began to form, shorting tools also emerged. On April 16, 2015, SCI 50 and China Securities Index (CSI) 500 futures were officially launched. In May and June, when both the stock market and leverage were at a high position, selling offers of CSI 500 futures also reached two peaks. During the fluctuation in May and June, relying on the fluctuation, the short side controlled stock indexes to slump and knocked down large-cap stocks, by going short stock index futures and created a new shot point. In July, as SMEs board and GEB stocks suffered from measureless limits down, contracts headed by CSI 500 futures shrunk dramatically by $12 \%$. Since CSI 500 can accurately reflect the trend of most stocks, people can only issue more CSI 500 short orders for hedging. A large number of short orders further intensified the panic on the stock market and formed a vicious circle. 
Rebound (Time: October 8- December 11). Since the end of National Day in China, the weighted rise of all A-shares was 18.01\%. Among individual stocks, 2436 stocks rose and 195 stocks fell. 659 stocks rose over 50\%. 85 stocks doubled. 92 stocks fell over $10 \%$.

Analysis: The rise in this stage was inseparable from bailouts launched by the government intensively in July. The bailouts launched by the government can be summarized as below:

(1) China Securities Finance Corporation Limited underwrote 120 billion yuan to enter the market, transfuse blood to public offerings and maintain the stability of capital market.

(2) Suspended the issuance of IPO and reduced the outflow of capitals in the stock market.

(3) CSRC, the Ministry of Finance and SASAC required listed companies not to underweight within 6 months and encourage overweight, repurchase and employee shareholding.

(4) Revised new rules about securities margin trading and lowered transaction costs;

(5) Audited suspected market manipulations specially. Cracked down malicious shorting by law seriously. If such behaviors were involved with crimes, brought to a public security organ for investigation resolutely.

Analysis of Sector and Individual Stocks (Internet finance concept stocks as an example)

The "Internet+" concept launched by Prime Minister Li Keqiang was the hottest topic in 2015, especially after the top leadership issued a statement to endorse Internet finance. Many provincial and municipal governments launched Internet financial industry development plans and lifted a wave of "Internet +" concept stocks. In a bull market in the first half of 2015, Internet finance was the most dazzling star. From July 2014 to June 2014, Internet finance sector rose more than 500\%, ranking $1^{\text {st }}$ among all concept sector indexes. Even during the rebound after tumble from September to December, Internet finance indexes rose nearly 90\%. Below, with Eastmoney, whose rise was one of the industry's Top 10 for example, the author will analyze its changes of share price in 2015.

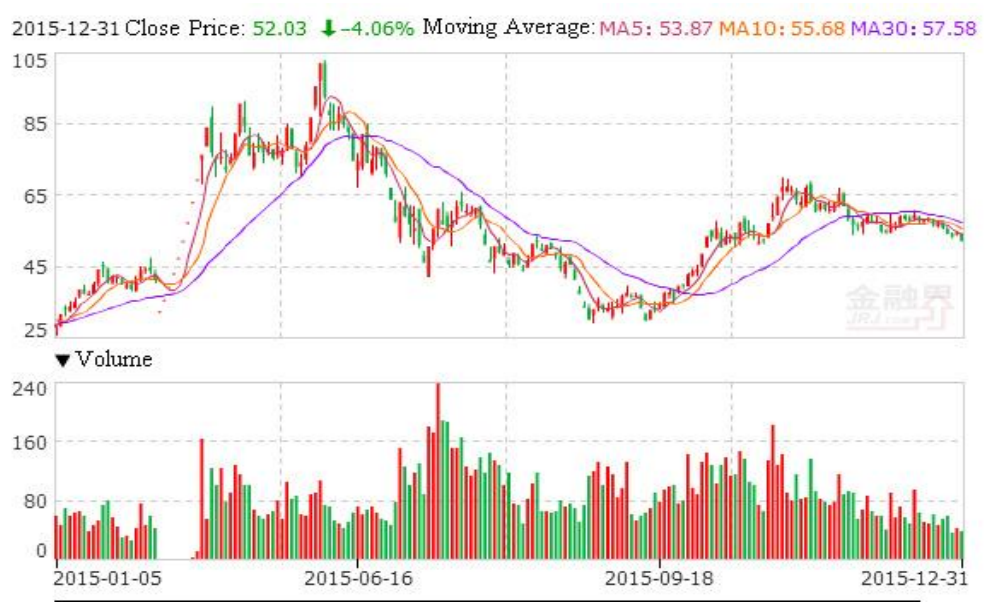

Figure 3. Price change of Eastmoney in 2015

From the perspective of share price, Eastmoney's share price rose from 35 yuan on January 9, 2015 to 83.95 yuan on April 30, peaking on June 5, 2015. The weekly closing price was 92.4 yuan. Compared with the original 35 yuan, it rose nearly 200\%. But with the outbreak of stock market crash, from June 12, Eastmoney's shares were always dominated by shorts. The share price fell all the way. On August 28, the share price dropped to 35.38 yuan, back to the level on January 9. From September 22, the share price began to rebound. According to weekly K-line observations, on September 22, the share price was 37.5 yuan and rose steadily later. On November 6 , the share price reached 64.66 yuan. Although later it fell slightly, by December 31, the share price has been stabilized around 52 yuan.

From the perspective of trading volume, the first half of 2015 was dominated by red bars, suggesting that the buy volume was greater than the sell volume. However, from June 12, on more occasions, the sell volume was greater than the buy volume. Accordingly, the share price fell all the way. Only on July 17, a red bar appeared, and the stock price rebounded. Later, the share price 
dropped again. We have good reason to believe that the soar of buy volume on July 17 had something to do with the government's bailouts. The fall continued to September 22. Since that day, in trading volume, the buy volume gradually overtook the sell volume. From September 22 to November 6, almost all of the buy volume was greater than the sell volume. Accordingly, the share price gradually picked up. Although later the sell volume surpassed the buy volume, shorts were not as powerful as before. Therefore, the share price was basically stable.

Analysis: As Eastmoney belonged to leading stocks in the Internet finance concept sector, so when Internet finance became the hottest topic in the first half of 2015, coincided with the boom of fundamentals of the stock market, Eastmoney's share price also rose with the tide, just like a pig flying in the draught. The share price rocketed from 35 yuan to 92.4 yuan all the way. This was closely related to the mad bull momentum formed by large-cap stocks.

With the overall slump of stock market in June and July, even the most powerful stock was encumbered inevitably. From 92.4 yuan in June to 36.38 yuan in August, the range of drop was as high as $200 \%$, partly due to the influence of large-cap stocks. In July, the government adopted lots of bailouts. But the main goal of authority was two barrels of oil, banking stocks and other heavyweight stocks. Therefore, Eastmoney, as an emerging concept stock, didn't inhibit the trend of decline.

However, as bailouts unfolded and a lot of capitals were invested in the market, the phenomenon of malicious shorting was controlled. The market order began to return to stable. Large-cap stock entered the stage of "maintaining stability". As Internet + concept stocks per se had huge potential, such kind of theme stocks began to rebound slowly. Therefore, from September, Eastmoney's share price began to restore stability.

\section{Summary}

The above two parts analyze the changes of stock market in 2015, from the variation trend of large-cap and the performance of individual stocks, respectively and draw the following conclusions:

(1) China's capital market is in an initial stage. The investment channel is single. Investors with extra money cannot choose suitable investment channels, so most people can only choose stock market as the only way of investment.

(2) China's stock market is still in the stage of development and immature yet. There are unreasonable insider trading, information asymmetry, imperfect trading mechanism and other defects on the market. Listed subjects, original shareholders and related service providers lack professional ethics, sell shares wildly when share prices fall and cause panic in the market. At the same time, the overall quality of investors is not high. They have a serious bandwagon and speculation psychology, pursue profits blindly, chase rises and slash falls and lead to large-scale stampedes when stock indexes fall. This phenomenon leads to an awkward situation: most investors who take out real money in the capital market lose, while most listed subjects, original shareholders and related service providers win. Investors in China's stock market, especially small and medium retail investors suffer the heaviest losses.

(3) China's entity economy hasn't recovered. There are many risks and bubbles underlying booms of stock market. Therefore, both emerging theme stocks and concept stocks of investment value have an artificially high PE ratio. Therefore, whichever stock you buy, you must be careful when buying.

(4) Individual stocks have a very close relationship with large-cap stocks. Moreover, performance is not direct proportion to stock prices. No matter how powerful or promising a company is, its share prices will be seriously affected by sharp fluctuations of large-cap stocks.

(5) After the boom and slump in 2015, the government implements more stringent regulations over the stock market. In 2016, the stock market will remain stable. Either rise or fall, the rollercoaster-like range of rise or fall in 2015 will not reappear. But due to the sluggish entity economy, the stock market would not rise dramatically. 


\section{References}

[1] Xingshu Zhou, Analysis and thinking of stock market disaster in China in year 2015, Money China, 2016(4):17-17

[2] Yingying Huang, Analysis and reflection based on the oscillating of Chinese stock market in 2015, Jiangsu Commercial Forum, 2016(7)

[3] Congcong Wang, Analysis the reason of boom and slump in Chinese stock market, Jiangsu Commercial Forum, 2016(2)

[4] Zhilin Zhen, Analysis of invest action under abnormal fluctuation in Chinese stock market, Economic research guide, 2016(7)

[5] Rong Zhang, Herd behavior in stock market-Based on Chinese circuit breaker, Contemporary Economic, 2016(10)

[6] Hongcai Xu, Xiangfeng Liu, Reason and countermeasures of fluctuation in Chinese stock and currency market

[7] Jijun He, The characteristic, causes and countermeasures of fluctuation in A-share market in China, Shandong University, 2010

[8] Xiangfeng Liu, Reason and countermeasures of sharply fluctuation in Chinese capital market recently, China development and observation, 2015(11):48-52

[9] Yuwen Hu, A-share market is facing directional big choices, , 2015(37):18-18

[10]Chi Ma, Research of the reason why price wave in A-share market and measures to stabilize, Xi'an XX University,2004 